\title{
Erratum to: Nanostructured Metal Oxides: Low Temperature Synthesis and Biomimetic Approaches
}

\author{
Sunkara V. Manorama • Pratyay Basak • \\ Rohit Kumar Rana • M. Lakshmi Kantam
}

Published online: 27 November 2012

(C) The National Academy of Sciences, India 2012

Erratum to: Proc. Natl. Acad. Sci., India, Sect. B Biol. Sci.

DOI 10.1007/s40011-012-0081-6

The original article published in the October issue Volume 82, Supplement 1 includes errors in the reference list which have been corrected as given below.

Under the section Conclusions, Ref. [192] should be Ref. [188].

Ref. No 27: Iler RK (1986) Inorganic colloids for forming intrastructures. In: Hench LL, Ulrich DR (eds)
Science of ceramic chemical processing. Wiley, New York, pp 3-20.

Ref. No 51: Gerfin T, Grätzel M, Walder L (1997) Molecular and supermolecular surface modification of nanocrystalline $\mathrm{TiO}_{2}$ films: charge separating and charge injecting devices. In: Karlin KD (ed) Molecular level artificial photosynthetic materials. Wiley, New York, pp 345-353.

Ref. No 94: Waingankar S, Kulkarni DS, Sagare MS (1997) Humidity sensing using soft ferrites. J Phys IV (Parts) [Suppl III]:155-156.
The online version of the original article can be found under doi:10.1007/s40011-012-0081-6.

S. V. Manorama · P. Basak · R. K. Rana · M. L. Kantam ( $ه)$ Inorganic and Physical Chemistry Division, CSIR-Indian Institute of Chemical Technology, Hyderabad 500607,

Andhra Pradesh, India

e-mail: mlakshmi@iict.res.in 